\title{
Effect of Losartan, an Angiotensin II Type 1 Receptor Antagonist on Cardiac Autonomic Functions of Rats During Acute and Chronic Inhibition of Nitric Oxide Synthesis
}

\author{
M. CHASWAL ${ }^{1}$, S. DAS ${ }^{1}$, J. PRASAD ${ }^{2}$, A. KATYAL ${ }^{3}$, A. K. MISHRA ${ }^{4}$, M. FAHIM ${ }^{5}$ \\ ${ }^{1}$ Department of Physiology, Vardhaman Mahavir Medical College \& Safdarjung Hospital, New \\ Delhi, India, ${ }^{2}$ Department of Cardiothoracic \& Vascular Surgery, Vardhaman Mahavir Medical \\ College \& Safdarjung Hospital, New Delhi, India, ${ }^{3}$ Department of Biochemistry, B.R. Ambedkar \\ Centre For Biomedical Research, University of Delhi, Delhi, India, ${ }^{4}$ Institute of Pathology, ICMR, \\ Safdarjung Hospital, New Delhi, India, ${ }^{5}$ Department of Physiology, Hamdard Institute of Medical \\ Sciences \& Research, Jamia Hamdard, New Delhi, India
}

Received July 9, 2011

Accepted December 2, 2011

On-line January 31, 2012

\section{Summary}

We studied the effect of losartan on baroreflex sensitivity (BRS) and heart rate variability (HRV) of adult Wistar rats during acute and chronic inhibition of nitric oxide synthesis by $\mathrm{N}^{G}$-nitro-Larginine methyl ester (L-NAME). Chronic L-NAME administration (50 mg/kg per day for 7 days, orally through gavage) increased mean arterial pressure (MAP), heart rate but significantly decreased BRS. In addition, a significant fall of standard deviation of normal RR intervals, total spectral power, high frequency spectral power and a rise of low frequency to high frequency (LF: HF) ratio was seen. Acute L-NAME administration (30 mg/kg, i.v. bolus dose) also raised MAP and impaired HRV but it was associated with augmented BRS for bradycardia reflex. Losartan treatment $(10 \mathrm{mg} / \mathrm{kg}$, i.v.) in both acute and chronic L-NAME treated rats, decreased MAP but the difference was not significant. On the other hand, losartan administration normalized depressed BRS for bradycardia reflex and significantly reduced LF to HF ratio in chronic L-NAME treated rats. But this improvement was not observed in acute L-NAME group. These results indicate importance of mechanisms other than renin-angiotensin system in the pressor response of both acute as well as chronic L-NAME. However, autonomic dysregulation especially following chronic L-NAME appears to be partly angiotensin dependent.

\section{Key words}

Losartan • L-NAME • Angiotensin II • Baroreflex sensitivity • Heart rate variability

\section{Corresponding author}

M. Fahim, Department of Physiology, Hamdard Institute of Medical Sciences \& Research, Jamia Hamdard, New Delhi, India. E-mail: vpciphysiology@yahoo.com

\section{Introduction}

Although hypertension is a major modifiable risk factor for cardiovascular diseases (Chobanian et al. 2003), its etiology remains unclear. Recent years have seen emergence of role of nitric oxide in regulation of blood pressure and nitric oxide deficiency is considered to be an important component of hypertension. Longterm administration of L-NAME, a potent competitive inhibitor of nitric oxide synthase (NOS), has been reported to produce sustained hypertension (Klahr 2001). Apart from its vasorelaxant action, nitric oxide is also an important regulator of cardiac autonomic control as it tonically restrains sympathetic tone and facilitates parasympathetic outflow to heart (Chowdhary and Townend 1999). Due to derangement of these functional effects of nitric oxide, a state of sympathetic over activation and parasympathetic deactivation characterizes several cardiovascular diseases (Schultz 2009). Cardiac autonomic functions are most often assessed by measuring BRS and HRV, both of which are noninvasive measures of autonomic influences on 
heart. Baroreflex responses in L-NAME induced hypertension have been examined by previous studies but precise nature of influence, inhibitory or stimulatory, are the subject of conflicting reports. While some reports have described a decreased sensitivity in the baroreflex control of heart rate (Souza et al. 2001), others reported either an increase or no change (Vasquez et al. 1994, Banting et al. 1996) in baroreflex sensitivity. In addition, only few studies have attempted HRV analysis after L-NAME hypertension (Mikhov et al. 1998, Souza et al. 2009). As acute and chronic administration of L-NAME produces different changes within the vasculature (Gardiner et al. 1990, Deng et al. 1993), it may be presumed that the extent of autonomic dysfunction may also vary with the duration of L-NAME treatment. However, to our knowledge, no previous study has systematically evaluated and compared the effects of acute as well as chronic inhibition of nitric oxide synthesis on the autonomic control of cardiovascular function in rats. In addition, the mechanism of autonomic dysfunction after L-NAME hypertension remains unresolved as to whether it is a direct effect of nitric oxide synthesis inhibition or there is involvement of other neurohumoral factors such as renin-angiotensin system. Previous studies have shown that hypertension following acute administration of L-NAME is not angiotensin dependent; in contrast hypertension accompanying chronic administration of L-NAME is reported to be at least partly dependent upon the renin-angiotensin system (Baylis et al. 1993, Pollock et al. 1993, Ortíz et al. 1998).

The purpose of the current study was therefore to investigate and compare possible alterations of the autonomic control of heart during acute and chronic inhibition of nitric oxide synthesis using L-NAME. We further sought to determine the role of renin-angiotensin system in this model by examining the ability of the angiotensin II type $1\left(\mathrm{AT}_{1}\right)$ receptor antagonist losartan to modify the changes produced by L-NAME.

\section{Materials and Methods}

\section{Animals}

Adult male Wistar albino rats weighing between 250-350 g were used. Animals were kept in 12:12-h lightdark cycle and received food and tap water ad libitum. All procedures conformed to the guidelines of the Committee for the Purpose of Control and Supervision of
Experiments on Animals (CPCSEA), India. Approval for experimental procedures was obtained from Institutional Animal Ethical Committee of B. R. Ambedkar Centre for Biomedical Research (ACBR), University of Delhi, India.

\section{Surgical procedure}

Prior to surgery, rats were anaesthetized using urethane dissolved in distilled water, injected intraperitoneally at a dose of $1 \mathrm{~g} / \mathrm{kg}$ of body weight. Rectal temperature of rat was maintained at around $37^{\circ} \mathrm{C}$. Tracheostomy was performed so as to allow for free breathing without any obstruction. Catheters were placed in femoral vein for drug injection and in femoral artery for measurement of arterial blood pressure via a pressure transducer (Statham $\mathrm{P}$ 23D). Before recording arterial blood pressure (ABP), pressure recording system was calibrated with the help of a mercury manometer. ABP and heart rate (HR) were measured after 20 min of stabilization period and recording was done on a Power Lab data-acquisition system (4SP, AD Instruments, Australia) with a computerized analysis program (Chart 5.4.2, AD Instruments, Australia).

\section{Measurement of BRS}

For measurement of BRS, phenylephrine (20 microgram $/ \mathrm{ml} / \mathrm{kg}$ ) and sodium nitroprusside (20 microgram $/ \mathrm{ml} / \mathrm{kg}$ ) were injected i.v. as bolus dose to cause respectively rise and fall in arterial blood pressure. Injections were separated by 15 -minute interval to allow the parameters to stabilize. The relationship between rise in systolic blood pressure (SBP) evoked by phenylephrine and associated bradycardia or fall in SBP evoked by sodium nitroprusside and associated tachycardia was assessed by regression analysis. The regression coefficient (slope of regression line) expressed as beats per minute per mm of mercury (bpm/mm $\mathrm{Hg}$ ) was taken as an index of BRS.

\section{Electrocardiogram (ECG) recording}

Bipolar limb lead II was used for recording ECG. Electrodes were placed subcutaneously and were connected through a bioamplifier (AD instruments, Australia) to the Power Lab data-acquisition system.

\section{Estimation of HRV}

HRV was assessed from each 5-minute ECG recording using HRV software (AD Instruments, Australia). From the surface ECG, the individual RR intervals were computed and $\mathrm{RR}$ variations were 
evaluated by time as well as frequency domain methods. Time domain parameter measured included standard deviation of normal RR intervals (SDNN). Frequency domain analysis was performed using fast Fourier transformation (FFT) technique. Specific frequency bands used for power spectrum included: total power (P: 0 to $3 \mathrm{~Hz}$ ), power in the low-frequency range (LF: 0.25 to $1 \mathrm{~Hz}$ ), high-frequency range (HF: 1 to $3 \mathrm{~Hz}$ ). LF to $\mathrm{HF}$ ratio $(\mathrm{LF} / \mathrm{HF})$ was calculated to estimate the sympatho-vagal balance. Different frequency bands were selected based on previous report (Baumert et al. 2007).

\section{Experimental protocols}

Protocol 1. Acute nitric oxide synthesis inhibition: effect of acute administration of $A T_{1}$ receptor antagonist losartan

Acute inhibition of nitric oxide synthesis was achieved by L-NAME (30 mg/kg i.v.). This dose is reported to produce maximum inhibition of nitric oxide synthesis and is known to evoke a maximal increase of blood pressure in rats (Frühbeck 1999).

After surgical procedure, rats were divided into following five groups for assessing the effects of acute nitric oxide synthesis inhibition and ability of losartan to reverse these effects. Each group comprised of 9 animals.

1) Control: After the baseline period, the animals received the vehicle $(0.9 \% \mathrm{NaCl}$, i.v. $)$ as a bolus injection. 20 minute after administration of vehicle, baseline MAP and HR were recorded. Estimation of BRS and HRV was done.

2) Acute losartan: After the baseline period, animals received losartan (10 $\mathrm{mg} / \mathrm{kg}$, i.v.). Repeat measurements were made after 20 minute stabilization period.

3) Acute losartan + acute L-NAME: After the baseline period, losartan $(10 \mathrm{mg} / \mathrm{kg}$, i.v. $)$ was injected. Following a rest period of $5 \mathrm{~min}$, L-NAME was injected as a bolus dose (30 mg/kg, i.v.). Estimation of BRS and HRV was done after 20 minutes of stabilization period.

4) Acute L-NAME: After the baseline period, animals received L-NAME (30 $\mathrm{mg} / \mathrm{kg}$, i.v.) as a bolus dose. Measurements of MAP and HR were made after 20 minute stabilization period. Estimation of BRS and HRV was done.

5) Acute L-NAME + acute losartan: After baseline period, L-NAME (30 mg/kg, i.v.) was injected as a bolus. After $5 \mathrm{~min}$, animals received losartan $(10 \mathrm{mg} / \mathrm{kg}$, i.v.). Repeat measurements were made after 20 minute stabilization period.
Protocol 2. Chronic nitric oxide synthesis inhibition: effect of acute administration of $A T_{1}$ receptor antagonist losartan

In this protocol we estimated the involvement of angiotensin II in the modifications of cardiac autonomic functions induced by chronic inhibition of nitric oxide synthesis. Rats were divided into four groups and each group had 7 animals:

1) Control: These rats received vehicle ie water administered through gavage for 7 days.

2) Chronic nitric oxide synthesis inhibition by L-NAME: Rats received daily L-NAME $50 \mathrm{mg} / \mathrm{kg}$ dissolved in water and administered through gavage for 7 days. The dose selection was on the basis of earlier study (Souza et al. 2001).

3) Acute administration of $\mathrm{AT}_{1}$ receptor antagonist losartan (10 mg/kg, i.v.).

4) Combined chronic L-NAME + acute losartan: Rats received daily L-NAME $50 \mathrm{mg} / \mathrm{kg}$ dissolved in water and administered through gavage for 7 days and acute administration of losartan $(10 \mathrm{mg} / \mathrm{kg}$, i.v.).

At the end of chronic treatment with L-NAME or vehicle, rats were anaesthetized with urethane and surgery was performed to insert arterial and venous catheter. In each of group after 20 minute of stabilization period, MAP and HR were recorded and measurement of BRS and HRV was done.

\section{Statistical analysis}

The results are presented as means \pm S.E.M. Statistical significance was calculated from KruskalWallis test with post hoc Dunn's test for adjustment of multiple comparisons. The value was considered significant at $\mathrm{p}<0.05$.

\section{Drugs}

Chemicals employed in the experimental protocol were L-NAME, phenylephrine hydrochloride, sodium nitroprusside, losartan and urethane. All chemicals were obtained from Sigma-Aldrich (USA).

\section{Results}

Hemodynamic parameters of L-NAME treated rats: effect of losartan on these parameters

As shown in Table 1, acute inhibition of nitric oxide synthesis by L-NAME in anaesthetized control rats caused a significant increase in MAP but did not affect the HR. Chronic administration of L-NAME resulted in 
significant elevation of MAP and also HR compared to vehicle- treated control rats. MAP and $\mathrm{HR}$ after $\mathrm{AT}_{1}$ receptor blockade by losartan were similar to unblocked control conditions in both acute and chronic L-NAME group. Post treatment of acute and chronic L-NAME treated hypertensive rats with losartan resulted in slight reduction of blood pressure but the difference was not statistically significant. When losartan was administered prior to acute L-NAME non significant reduction of pressor response of L-NAME with tachycardia was seen.

Table 1. Baseline hemodynamic parameters of animals studied.

\begin{tabular}{lcc}
\hline Treatment Group & $\begin{array}{c}\text { MAP } \\
(\mathbf{m m ~ H g})\end{array}$ & $\begin{array}{c}\text { HR } \\
\text { (beats/min) }\end{array}$ \\
\hline Acute L-NAME group & & \\
Control $(n=9)$ & $76.6 \pm 3.1$ & $336.1 \pm 11.1$ \\
Losartan $(n=9)$ & $60.8 \pm 1.9$ & $375.6 \pm 12.2$ \\
Losartan + L-NAME & $99.4 \pm 2.8^{\mathrm{F}}$ & $397.5 \pm 8.1^{\dagger *}$ \\
(n=9) & & \\
L-NAME $(n=9)$ & $136.9 \pm 2.5^{* \mathrm{~F}}$ & $339.4 \pm 9.1$ \\
L-NAME + Losartan & $107.2 \pm 4.8^{\mathrm{F}}$ & $357.5 \pm 5.2$ \\
(n=9) & & \\
Chronic L-NAME group & & \\
Control $(n=7)$ & $79.6 \pm 3.0$ & $326.4 \pm 12.0$ \\
Losartan $(n=7)$ & $72.2 \pm 1.5$ & $333.0 \pm 10.8$ \\
L-NAME $(n=7)$ & $143.5 \pm 4.8^{*} \mathrm{~F}$ & $376.6 \pm 6.9 *$ \\
L-NAME + Losartan & $87.8 \pm 3.8$ & $334.6 \pm 13.2$ \\
(n=7) & & \\
\hline
\end{tabular}

MAP, mean arterial pressure; HR, heart rate; $n$, number of rats. Values are given as means \pm S.E.M. ${ }^{*} p<0.05$ versus Control, ${ }^{\mathrm{F}} \mathrm{p}<0.05$ versus Losartan, ${ }^{\dagger} \mathrm{p}<0.05$ versus Acute L-NAME.

Effect of L-NAME on arterial baroreceptor mediated blood pressure regulatory mechanism: effect of losartan on these responses

Baroreflex sensitivity was measured as ratio of bradycardia response to rise in arterial pressure by phenylephrine or as a ratio of tachycardia response to fall in pressure by sodium nitroprusside. As shown in Figure $1 \mathrm{~A}$ and $\mathrm{B}$, acute administration of L-NAME, compared to control rats was associated with augmented baroreflex sensitivity for bradycardia reflex $(2.6 \pm 0.1$ versus $1.8 \pm 0.1$ $\mathrm{bpm} / \mathrm{mm} \mathrm{Hg}, \quad \mathrm{p}<0.05)$ and preserved sensitivity for tachycardia reflex $(1.9 \pm 0.2$ versus $1.5 \pm 0.1 \mathrm{bpm} / \mathrm{mm} \mathrm{Hg}$, $\mathrm{p}>0.05)$. Losartan treatment, both pre and post did not alter baroreflex responses of acute L-NAME. On the other hand, compared to vehicle treated control rats, chronic L-NAME administration markedly reduced the sensitivity for bradycardia reflex $(2.0 \pm 0.2$ versus $0.8 \pm 0.05 \mathrm{bpm} / \mathrm{mm} \mathrm{Hg}, \mathrm{p}<0.05)$ as well as tachycardia reflex $(1.5 \pm 0.1$ versus $0.7 \pm 0.06 \mathrm{bpm} / \mathrm{mm} \mathrm{Hg}, \mathrm{p}<0.05)$ (Fig. 2A, Fig. 2B respectively). Losartan treatment significantly improved baroreflex sensitivity for bradycardia reflex in chronic L-NAME treated rats $(1.9 \pm 0.1$ versus $0.8 \pm 0.05 \mathrm{bpm} / \mathrm{mm} \mathrm{Hg}, \mathrm{p}<0.05)$ but baroreflex index for tachycardia reflex remained unchanged $(1.2 \pm 0.1 \mathrm{bpm} / \mathrm{mm} \mathrm{Hg}$ ) (Fig. 2A, Fig. 2B respectively).

Effect of L-NAME on components of heart rate variability: effect of losartan on these responses

As indicated in Figure 3, acute L-NAME treated rats showed a significant decline of SDNN (2.2 \pm 0.1 versus $3.8 \pm 0.3 \mathrm{~ms}, \mathrm{p}<0.05)$. Similar decrement of SDNN was seen after chronic L-NAME treatment $(2.0 \pm 0.1$ versus $4.1 \pm 0.3 \mathrm{~ms}, \mathrm{p}<0.05)$. No change in SDNN of both acute as well as chronic L-NAME treated rats was observed after losartan administration. Figure 4 depicts a significant decrease of total power $(3.8 \pm 0.4$ versus $\left.8.2 \pm 0.7 \mathrm{~ms}^{2}, \mathrm{p}<0.05\right)$, spectral power in HF band $(0.9 \pm 0.1$ versus $\left.4.5 \pm 0.4 \mathrm{~ms}^{2}, \mathrm{p}<0.05\right)$ and increase of $\mathrm{LF}$ to $\mathrm{HF}$ ratio $(0.6 \pm 0.09$ versus $0.2 \pm 0.02, \mathrm{p}<0.05)$ following acute L-NAME treatment of control rats. However, no difference in LF band was observed. Losartan treatment, both pre and post in acute L-NAME treated rats, did not alter spectral components of HRV. A similar trend was seen following chronic L-NAME treatment (Fig. 5) with decrease of total power $\left(3.0 \pm 0.3\right.$ versus $8.6 \pm 0.7 \mathrm{~ms}^{2}$, $\mathrm{p}<0.05)$, HF spectral power $\left(1.2 \pm 0.1\right.$ versus $4.5 \pm 0.6 \mathrm{~ms}^{2}$, $\mathrm{p}<0.05)$ and rise of $\mathrm{LF}$ to $\mathrm{HF}$ ratio $(0.4 \pm 0.05$ versus $0.2 \pm 0.01, \mathrm{p}<0.05)$. In addition, chronic L-NAME treatment did not change LF spectral power. Losartan treatment restored LF to HF ratio $(0.2 \pm 0.02)$ in chronic L-NAME treated animals.

\section{Discussion}

In addition to regulation of vascular smooth muscle tone, nitric oxide also modulates autonomic flow to heart thereby playing an important role in cardiovascular homeostasis. Inhibition of nitric oxide synthesis by L-arginine analogues such as L-NAME produces hypertension, usually accompanied by changes in autonomic function. 


\begin{tabular}{|c|c|}
\hline \multicolumn{2}{|c|}{$\square$ Control } \\
\hline & Losartan \\
\hline 金 & Losartan + L-NAME \\
\hline$\notin$ & L-NAME \\
\hline 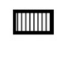 & L-NAME + Losartan \\
\hline
\end{tabular}

A
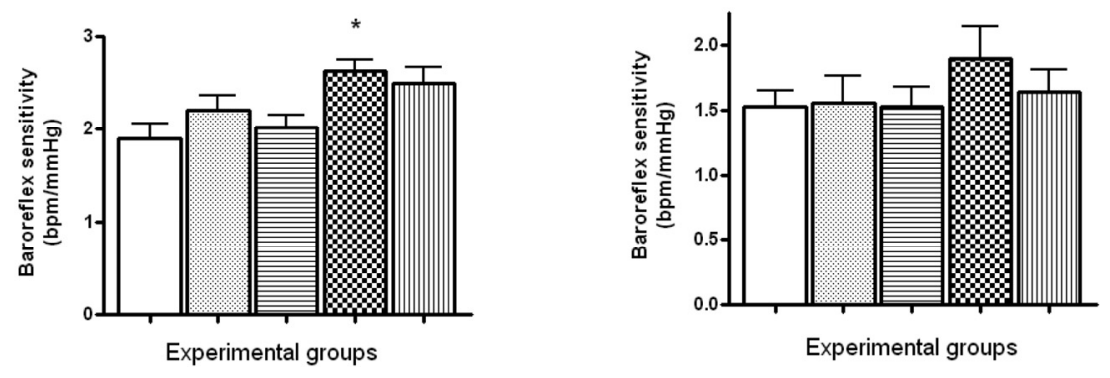

Control

Losartan

\& L-NAME

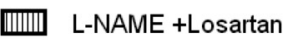

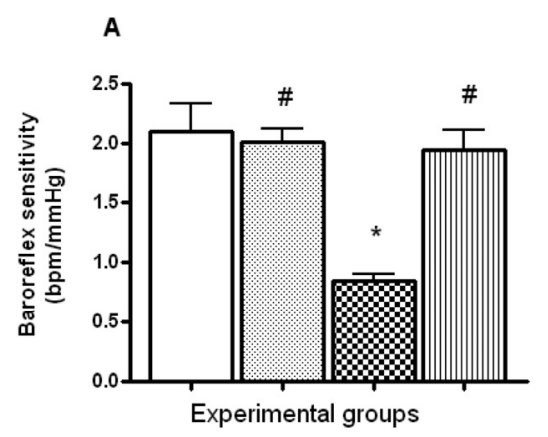

B

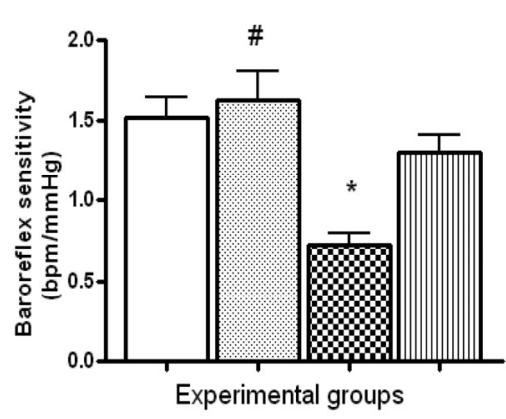

Control

Losartan

Losartan + L-NAME

\& L-NAME

IIIII) L-NAME + Losartan

A

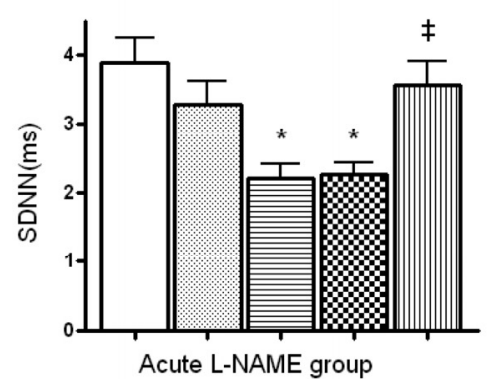

B

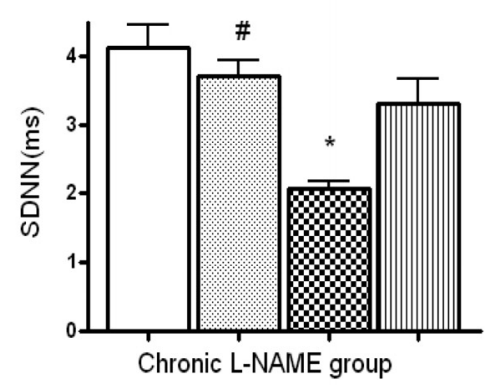

Fig. 1. Effect of losartan on baroreflex responses of acute L-NAME treated rats. (A) bradycardia response to rise in pressure by phenylephrine (B) tachycardia response to fall in pressure by sodium nitroprusside. Values are means \pm S.E.M. $* p<0.05$ versus Control.
Fig. 2. Effect of losartan on baroreflex responses of chronic L-NAME treated rats. (A) bradycardia response to rise in pressure by phenylephrine (B) tachycardia response to fall in pressure by sodium nitroprusside. Values are means \pm S.E.M. $* p<0.05$ versus Control, ${ }^{*} \mathrm{p}<0.05$ versus L-NAME.
Fig. 3. Effect of losartan on SDNN values of (A) acute L-NAME and (B) chronic L-NAME treated rats. SDNN, standard deviation of normal RR interval. Values are means \pm S.E.M. $* p<0.05$ versus Control, ${ }^{\#} p<0.05$ versus $L-N A M E,{ }^{\ddagger} p<0.05$ versus Losartan + L-NAME. 

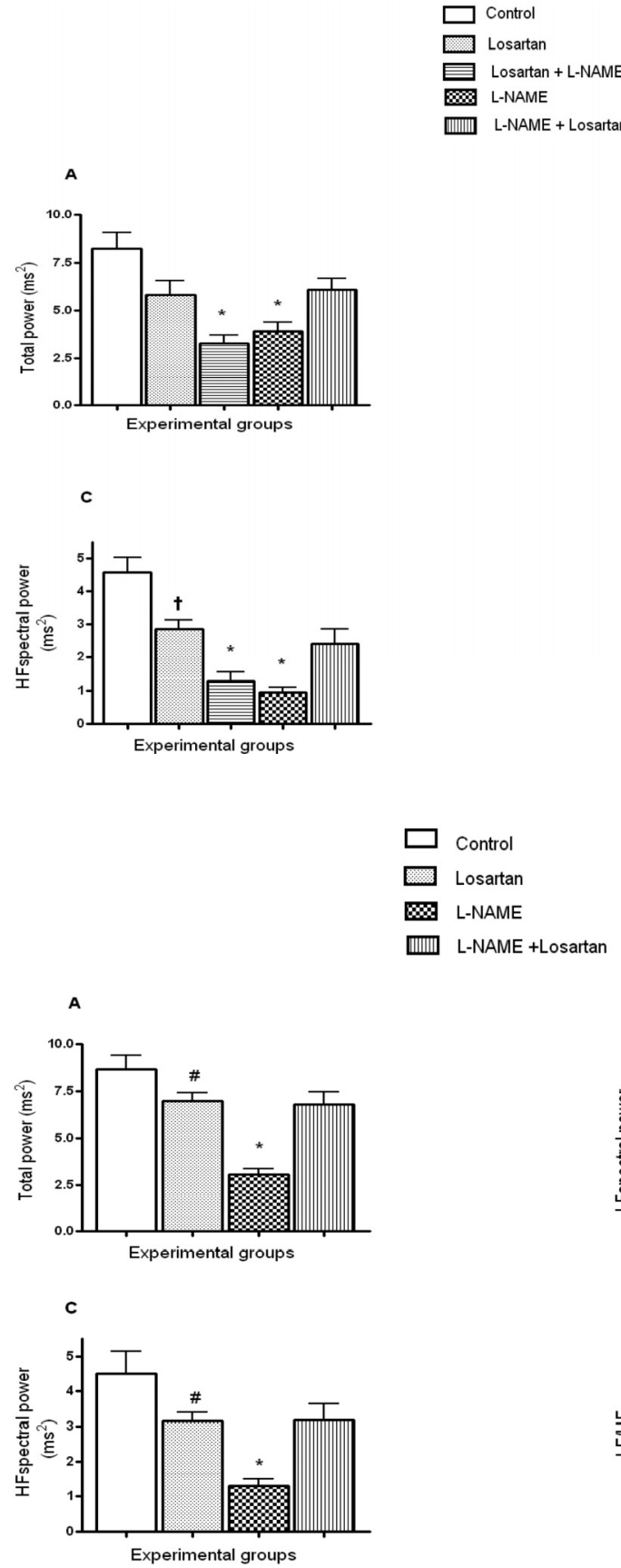
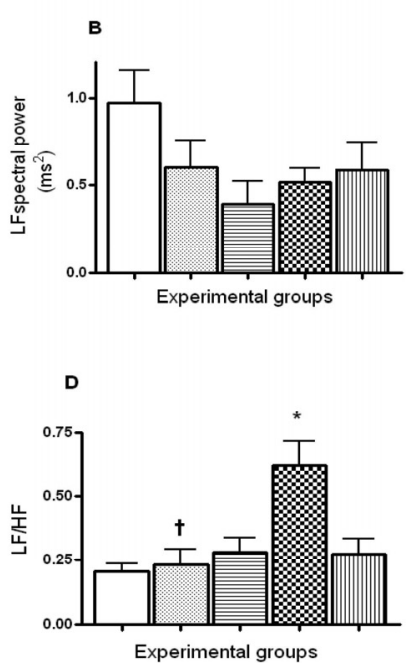

Fig. 5. Effect of losartan on spectral components of heart rate variability in chronic L-NAME treated rats. (A) total power of HRV spectrum; (B) LF, low frequency spectral power; (C) HF, high frequency spectral power; (D) LF to HF ratio. Values are means \pm S.E.M. $* p<0.05$ versus Control, ${ }^{*} \mathrm{p}<0.05$ versus L-NAME.
As suggested by earlier reports, vascular changes accompanying L-NAME hypertension are time dependent (Gardiner et al. 1990, Deng et al. 1993) and in contrast to acute L-NAME administration, blood pressure elevation following chronic administration of L-NAME, is said to be angiotensin dependent (Baylis et al. 1993, Pollock et al. 1993). Our results also suggest the existence of differential interaction between nitric oxide and angiotensin II depending on the duration of nitric oxide synthesis inhibition. To our knowledge, this is the first study in which cardiac autonomic responses following acute and chronic administration of L-NAME are
Fig. 4. Effect of pre and post treatment with losartan on spectral components of heart rate variability in acute L-NAME treated rats.
(A) total power of HRV spectrum; (B) LF, low frequency spectral power; (C) HF, high frequency spectral power; (D) LF to HF ratio. Values are means \pm S.E.M. $* p<0.05$ versus Control, ${ }^{\dagger} p<0.05$ versus L-NAME.
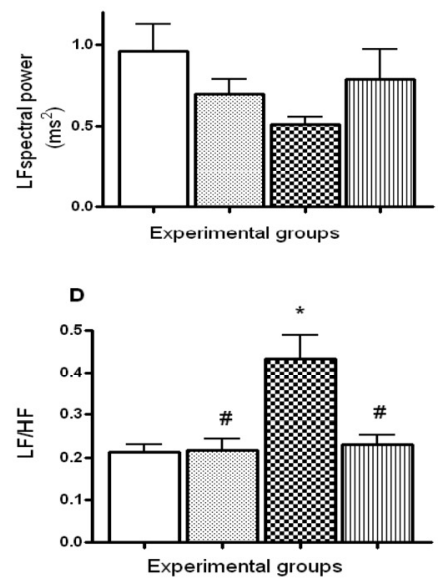

compared and role of renin-angiotensin system in these changes is defined.

The major findings of the present study are: (1) Acute as well as chronic administration of L-NAME increased blood pressure. The pressor effect induced by chronic L-NAME was accompanied by tachycardia while no significant change in heart rate resulted after acute L-NAME. (2) BRS was markedly attenuated by chronic administration of L-NAME whereas acute L-NAME augmented BRS for bradycardia reflex. (3) Marked decrement of SDNN, HF spectral power and rise in LF to HF ratio was seen after both acute as well as chronic 
L-NAME treatment. (4) Treatment with losartan decreased pressor response of acute as well as chronic L-NAME but the difference was not significant. (5) Losartan treatment restored BRS to bradycardia reflex and LF to HF ratio in chronic L-NAME treated rats but had no effect on acute L-NAME treated rats.

Demonstration of pressor response following both acute and chronic administration of L-NAME is an expected finding and is in agreement with earlier reports (Serogin et al. 1998, Eldesoky 2006, Biancardi et al. 2007). However, the precise mechanism of L-NAME induced pressure rise remains ill defined. Our study showed that acute losartan did not significantly reduce the pressor effect of acute as well as chronic L-NAME, thus suggesting that renin-angiotensin system is not primary mechanism contributing to L-NAME induced hypertension which may either be due to inhibition of direct vasorelaxant action of nitric oxide or may involve participation of other neurohumoral mechanisms. Our results are in agreement to earlier reports (Nafrialdi et al. 1994, Sigmon et al. 1994) which showed no effect of losartan on acute L-NAME induced blood pressure elevation. Another report by Bank et al. (1994) demonstrated failure of angiotensin II receptor antagonist in reducing blood pressure of rats following chronic nitric oxide inhibition. However, there are reports which contradict our findings (Pollock et al. 1993, Kalliovalkama et al. 1999) as they reported reversal of L-NAME hypertension by losartan. The discrepancies can be attributed to difference in route of administration such as oral versus intravenous, the dose of the NOS inhibitor used and the animal studied. In the study by Kalliovalkama et al. (1999) dose of losartan used was $20 \mathrm{mg} / \mathrm{kg}$ which was higher compared to dose of $10 \mathrm{mg} / \mathrm{kg}$ in our study. Besides this, study by Kalliovalkama et al. (1999) and Pollock et al. (1993) employed chronic oral administration of losartan in contrast to the use of acute intravenous bolus dose of losartan in our study. Losartan is known to modulate NOS isoforms (Manucha et al. 2004) and a study by Roccatello et al. (2000) suggested an increase in blood nitric oxide levels after losartan therapy in patients of nephropathy. Therefore, it is possible that the chronic administration of losartan is associated with higher production of nitric oxide as compared to its acute injection, thus explaining the discrepant results.

In addition to pressor effect, autonomic dysfunction is another frequent accompaniment of L-NAME induced hypertension. In the present study, non invasive autonomic function assessment by means of BRS and HRV revealed significant impairment of cardiac autonomic functions in acute as well as chronic L-NAME treated rats. Consistent with some previous reports (Souza et al. 2001, 2009), we observed significant attenuation of BRS after chronic L-NAME treatment. In contrast to suppressed baroreceptor responses after chronic L-NAME, acute administration of L-NAME resulted in enhanced BRS for bradycardia reflex. This is in agreement with earlier study of Peotta et al. (2001) and reflects the importance of time course of L-NAME treatment in determining the effect of nitric oxide inhibition on baroreceptor responses. Difference in baroreceptor responses after chronic as compared to acute administration of L-NAME could be due to sustained rise in sympathetic activity on long term treatment with L-NAME in contrast to a transient increase following acute L-NAME. Sustained increase of sympathetic nerve activity is known to exert a tonic restrain on distensibility of vessels including those where baroreceptors are located (Lacolley et al. 1995, Mangoni et al. 1997). Since distensibility determines mechanoreceptor stretch and afferent discharge from baroreceptors (Mircoli et al. 2002) the sensitivity of baroreceptors would reduce consequent to enhanced sympathetic activity in chronic L-NAME treated rats. In addition, possibly during acute administration of L-NAME, baroreceptor reflex responsiveness remained unchanged. Therefore, with raised pressure following L-NAME, further small rise of pressure induced by phenylephrine increased stretch of baroreceptor region causing a larger reflex bradycardia. But this was not seen after chronic L-NAME as baroreceptor responsiveness was reduced and baroreceptor might have reset to sustain higher pressure. Administration of losartan improved BRS for bradycardia reflex in chronic L-NAME treated rats. Similar improvement of baroreflex function by losartan has been reported in spontaneously hypertensive rats (Azevedo et al. 2003) and also in coarcted hypertensive rats (Santos et al. 1995). Reversal of baroreflex responses following losartan treatment as seen in chronic L-NAME group was however not demonstrated in acute L-NAME group as both pre or post treatment with losartan was found to have no effect on BRS of acute L-NAME treated rats of our study. Several investigators have shown that hypertension induced by chronic administration of L-NAME in contrast to acute L-NAME is reninangiotensin system dependent (Lahera et al. 1991, Morton et al. 1993). It is also well established that 
angiotensin II attenuates baroreflex control of heart rate and increases sympathetic activity (Guo and Abboud 1984, Mace et al. 1985, McMullan et al. 2007). Therefore, higher sensitivity to angiotensin II after chronic L-NAME administration (Yang et al. 1996) may be responsible for restoration of BRS in chronic L-NAME treated rats.

Time and frequency domain analysis of HRV also reinforced the existence of cardiac autonomic dysfunction in L-NAME treated rats. Relative to control animals, treatment with either acute or chronic L-NAME significantly reduced SDNN, total spectral power, HF spectral power and increased LF to HF ratio. These changes indicate a shift of sympathovagal balance towards sympathetic predominance and reduced vagal tone. The tachycardia observed after chronic L-NAME treatment may perhaps be a consequence of sympathetic over activity in these rats. Effects of nitric oxide inhibition on HRV have been controversial as one report suggested reduction of spectral density in LF range following L-NAME infusion in healthy humans (Castellano et al. 1995) whereas results of another study showed an increase in LF and fall in HF normalized component after chronic L-NAME hypertension in rats (Balbinott et al. 2005). Study by Souza et al. (2001) reported a reduction of SDNN, LF power density and also of LF to HF ratio. Our results are in partial agreement to these studies. The difference in dose and duration of L-NAME treatment used and species studied may provide explanation for discrepant results thus observed. In addition, we have demonstrated for the first time that $\mathrm{AT}_{1}$ receptor blocker losartan normalized $\mathrm{LF}$ to $\mathrm{HF}$ ratio in chronic L-NAME treated rats but had no such effect in acute L-NAME treated group. As stated above, in contrast to the effects of acute inhibition, long term nitric oxide inhibition is reported to result in hypersensitivity to neurohumoral factors such as angiotensin II (Qiu et al. 1994) and this increased sensitivity may explain differential effect of losartan on autonomic effects of L-NAME depending on duration of L-NAME treatment.

To summarize, the present study demonstrated autonomic dysregulation accompanying the blood pressure rise after acute as well as chronic L-NAME treatment of Wistar rats. Further, acute inhibition of the renin-angiotensin system by $\mathrm{AT}_{1}$ receptor blocker losartan could not reduce the hypertensive effect of either acute or chronic L-NAME but it restored the attenuated BRS for bradycardia reflex and LF to HF ratio in chronic L-NAME treated rats. These findings support the hypothesis that chronic inhibition of nitric oxide synthesis is at least partly dependent on reninangiotensin system.

\section{Conflict of Interest}

There is no conflict of interest.

\section{Acknowledgements}

The support provided by Vardhaman Mahavir Medical College \& Safdarjung Hospital, B.R.Ambedkar Centre for Biomedical Research and Department of Physiology, V.P. Chest Institute is thankfully acknowledged.

\section{References}

AZEVEDO LF, BRUM PC, MATTOS KC, JUNQUIERA CM, RONDON MU, BARRETTO AC, NEGRÃO CE: Effects of losartan combined with exercise training in spontaneously hypertensive rats. Braz J Med Biol Res 36: 1595-1603, 2003.

BALBINOTT AW, IRIGOYEN MC, BRASILEIRO-SANTOS MS, ZOTTIS B, LIMA NG, PASSAGLIA J, SCHAAN BD: Dose-dependent autonomic dysfunction in chronic L-NAME-hypertensive diabetic rats. J Cardiovasc Pharmacol 46: 563-569, 2005.

BANK N, AYNEDJIAN HS, KHAN GA: Mechanism of vasoconstriction induced by chronic inhibition of nitric oxide in rats. Hypertension 24: 322-328, 1994.

BANTING JD, WISEMAN SL, ADAMS MA: Hypertension without cardiac hypertrophy does not induce a cardiac baroreflex deficit. J Hypertens 14: 1209-1214, 1996.

BAUMERT M, NALIVAIKO E, ABBOTT D: Effects of vagal blockade on the complexity of heart rate variability in rats. In: IFMBE Proceedings, 11th Mediterranean Conference on Medical and Biomedical Engineering and Computing. T JARM, P KRAMAR, A ŽUPANIČ (eds), Ljubljana, Slovenia, 2007, pp 26-29.

BAYLIS C, ENGELS K, SAMSELL L, HARTON P: Renal effects of acute endothelial-derived relaxing factor blockade are not mediated by angiotensin II. Am J Physiol 264: F74-F78, 1993. 
BIANCARDI VC, BERGAMASCHI CT, LOPES OU, CAMPOS RR: Sympathetic activation in rats with L-NAME induced hypertension. Braz J Med Biol Res 40: 401-408, 2007.

CASTELLANO M, RIZZONI D, BESCHI M, MUIESAN ML, PORTERI E, BETTONI G, SALVETTI M, CINELLI A, ZULLI R, AGABITI-ROSEI E: Relationship between sympathetic nervous system activity, baroreflex and cardiovascular effects after acute nitric oxide synthesis inhibition in humans. J Hypertens 13: 1153-1161, 1995.

CHOBANIAN AV, BAKRIS GL, BLACK HR, CUSHMAN WC, GREEN LA, IZZO JL JR, JONES DW, MATERSON BJ, OPARIL S, WRIGHT JT JR, ROCCELLA EJ, THE NATIONAL HIGH BLOOD PRESSURE EDUCATION PROGRAM COORDINATING COMMITTEE: Seventh report of the Joint National Committee on Prevention, Detection, Evaluation, and Treatment of High Blood Pressure. Hypertension 42: 1206-1252, 2003.

CHOWDHARY S, TOWNEND JN: Role of nitric oxide in the regulation of cardiovascular autonomic control. Clinical Science 97: 5-17, 1999.

DENG LY, THIBAULT G, SCHIFFRIN EL: Effect of hypertension induced by nitric oxide synthase inhibition on structure and function of resistance arteries in the rat. Clin Exp Hypertens 15: 527-537, 1993.

ELDESOKY ES: Effect of acute inhibition of nitric oxide synthesis by L-NAME on cardiovascular responses following peripheral autonomic blockade in rabbits. Fundam Clin Pharmacol 20: 239-245, 2006.

FRÜHBECK G: Pivotal role of nitric oxide in the control of blood pressure after leptin administration. Diabetes 48 : 903-908, 1999.

GARDINER SM, COMPTON AM, KEMP PA, BENNETT T: Regional and cardiac haemodynamic effects of $\mathrm{N}^{\mathrm{G}}$-nitroL-arginine methyl ester in conscious, Long Evans rats. Br J Pharmacol 101: 625-631, 1990.

GUO GB, ABBOUD FM: Angiotensin II attenuates baroreflex control of heart rate and sympathetic activity. Am $J$ Physiol Heart Circ Physiol 246: H80-H89, 1984.

KALLIOVALKAMA J, JOLMA P, TOLVANEN JP, KÄHÖNEN M, HUTRI-KÄHÖNEN N, WU X, HOLM P, PÖRSTI I: Arterial function in nitric oxide-deficient hypertension: influence of long- term angiotensin II receptor antagonism. Cardiovasc Res 42: 773-782, 1999.

KLAHR S: The role of nitric oxide in hypertension and renal disease progression. Nephrol Dial Transplant 16: 60-62, 2001.

LACOLLEY P, GLASER E, CHALLANDE P, BOUTOUYRIE P, MIGNOT JP, DURIEZ M, LEVY B, SAFAR M, LAURENT S: Structural changes and in situ aortic pressure-diameter relationship in long-term chemical sympathectomized rats. Am J Physiol 269: H407-H416, 1995.

LAHERA V, SALOM MG, MIRANDA-GUARDIOLA F, MONCADA S, ROMERO JC: Effects of N $\mathrm{N}^{\mathrm{G}}$-nitro-Larginine methyl ester on renal function and blood pressure. Am J Physiol 261: F1033-F1037, 1991.

MACE PJ, WATSON RD, SKAN W, LITTLER WA: Inhibition of the baroreceptor heart rate reflex by angiotensin II in normal man. Cardiovasc Res 19: 525-527, 1985.

MANGONI AA, MIRCOLI L, GIANNATTASIO C, MANCIA G, FERRARI AU: Effect of sympathectomy on mechanical properties of common carotid and femoral arteries. Hypertension 30: 1085-1088, 1997.

MANUCHA W, OLIVEROS L, CARRIZO L, SELTZER A, VALLÉS P: Losartan modulation on NOS isoforms and COX-2 expression in early renal fibrogenesis in unilateral obstruction. Kidney Int 65: 2091-2107, 2004.

MCMULLAN S, GOODCHILD AK, PILOWSKY PM: Circulating angiotensin II attenuates the sympathetic baroreflex by reducing the barosensitivity of medullary cardiovascular neurones in the rat. J Physiol 582: 711-722, 2007.

MIKHOV D, MARKOVA P, GIRCHEV R: Spectral analysis of heart rate and arterial pressure variability after nitric oxide synthase inhibition. Acta Physiol Pharmacol Bulg 23: 79-84, 1998.

MIRCOLI L, FEDELE L, BENETTI M, BOLLA GB, RADAELLI A, PERLINI S, FERRARI AU: Preservation of the baroreceptor heart rate reflex by chemical sympathectomy in experimental heart failure. Circulation 106: 866 $872,2002$.

MORTON JJ, BEATTIE EC, SPEIRS A, GULLIVER F: Persistent hypertension following inhibition of nitric oxide formation in the young Wistar rat: role of renin and vascular hypertrophy. J Hypertens 11: 1083-1088, 1993.

NAFRIALDI N, JOVER B, MIMRAN A: Endogenous vasoactive systems and the pressor effect of acute N omeganitro-L-arginine methyl ester administration. J Cardiovasc Pharmacol 23: 765-771, 1994. 
ORTÍZ MC, FORTEPIANI LA, RUIZ-MARCOS FM, ATUCHA NM, GARCÍA-ESTAÑ J: Role of AT ${ }_{1}$ receptors in the renal papillary effects of acute and chronic nitric oxide inhibition. Am J Physiol Regul Integr Comp Physiol 274: R760- R766, 1998.

PEOTTA VA, VASQUEZ EC, MEYRELLES SS: Cardiovascular neural reflexes in L-NAME-induced hypertension in mice. Hypertension 38: 555-559, 2001.

POLLOCK DM, POLAKOWSKI JS, DIVISH BJ, OPGENORTH TJ: Angiotensin blockade reverses hypertension during long-term nitric oxide synthase inhibition. Hypertension 21: 660-666, 1993.

QIU C, ENGELS K, BAYLIS C: Angiotensin II and alpha 1-adrenergic tone in chronic nitric oxide blockade-induced hypertension. Am J Physiol Regul Integr Comp Physiol 266: 1470-1476, 1994.

ROCCATELlO D, MENGOZZI G, GIGLIOLA G, ROSSI D, MOSSO R, CACACE G, POLLONI R, CESANO G, PICCIOTTO G, PARADISI L, BANCALE E, PICCOLI G, SENA LM : Effects of angiotensin II blockade on nitric oxide blood levels in IgA nephropathy. Nephrol Dial Transplant 15: 988-993, 2000.

SANTOS CM, PONTIERI V, NETO ML, MICHELINI LC: Losartan improves baroreflex control of heart rate of coarcted hypertensive rats. Am J Physiol Heart Circ Physiol 269: H812-H818, 1995.

SCHULTZ HD: Nitric oxide regulation of autonomic function in heart failure. Curr Heart Fail Rep 6: 71-80, 2009.

SEROGIN KE, HATTON DC, CHI Y, LUFT FC: Chronic nitric oxide inhibition with L-NAME: effects on autonomic control of the cardiovascular system. Am J Physiol Regul Integr Comp Physiol 274: R367-R374, 1998.

SIGMON DH, NEWMAN JM, BEIERWALTES WH: Angiotensin II: endothelium-derived nitric oxide interaction in conscious rats. J Am Soc Nephrol 4: 1675-1682, 1994.

SOUZA HCD, BALLEJO G, SALGADO MCO, DIAS DA SILVA VJ, SALGADO HC: Cardiac sympathetic overactivity and decreased baroreflex sensitivity in L-NAME hypertensive rats. Am J Physiol Heart Circ Physiol 280: H844-H850, 2001.

SOUZA HCD, DE ARAÚJO JE, MARTINS-PINGE MC, COZZA IC, MARTINS-DIAS DP: Nitric oxide synthesis blockade reduced the baroreflex sensitivity in trained rats. Auton Neurosci 150: 38-44, 2009.

VASQUEZ EC, CUNHA RS, CABRAL AM: Baroreceptor reflex function in rats submitted to chronic inhibition of nitric oxide synthesis. Braz J Med Biol Res 27: 767-774, 1994.

YANG Y, MACDONALD GJ, DUGGAN KA: Changes in angiotensin II metabolism contribute to the increased pressor response to angiotensin after chronic treatment with L-NAME in the spontaneously hypertensive rat Clin Expl Pharmacol Physiol 23: 611-613, 1996. 